University of Vermont

UVM ScholarWorks

Rubenstein School of Environment and Natural Rubenstein School of Environment and Natural Resources Faculty Publications

8-1-2011

\title{
The high costs of conserving Southeast Asia's lowland rainforests
}

\author{
Brendan Fisher \\ Princeton School of Public and International Affairs \\ David P. Edwards \\ University of Leeds \\ Xingli Giam \\ Princeton University \\ David S. Wilcove \\ Princeton School of Public and International Affairs
}

Follow this and additional works at: https://scholarworks.uvm.edu/rsfac

Part of the Climate Commons, Community Health Commons, Human Ecology Commons, Nature and Society Relations Commons, Place and Environment Commons, and the Sustainability Commons

\section{Recommended Citation}

Fisher B, Edwards DP, Giam X, Wilcove DS. The high costs of conserving Southeast Asia's lowland rainforests. Frontiers in Ecology and the Environment. 2011 Aug;9(6):329-34.

This Article is brought to you for free and open access by the Rubenstein School of Environment and Natural Resources at UVM ScholarWorks. It has been accepted for inclusion in Rubenstein School of Environment and Natural Resources Faculty Publications by an authorized administrator of UVM ScholarWorks. For more information, please contact scholarworks@uvm.edu. 


\title{
The high costs of conserving Southeast Asia's lowland rainforests
}

\author{
Brendan Fisher ${ }^{*}$, David P Edwards ${ }^{2}$, Xingli Giam ${ }^{3}$, and David S Wilcove ${ }^{1,3}$
}

\begin{abstract}
Mechanisms that mitigate greenhouse-gas emissions via forest conservation have been portrayed as a cost-effective approach that can also protect biodiversity and vital ecosystem services. However, the costs of conservation - including opportunity costs - are spatially heterogeneous across the globe. The lowland rainforests of Southeast Asia represent a unique nexus of large carbon stores, imperiled biodiversity, large stores of timber, and high potential for conversion to oil-palm plantations, making this region one where understanding the costs of conservation is critical. Previous studies have underestimated the gap between conservation costs and conversion benefits in Southeast Asia. Using detailed logging records, cost data, and species-specific timber auction prices from Borneo, we show that the profitability of logging, in combination with potential profits from subsequent conversion to palm-oil production, greatly exceeds foreseeable revenues from a global carbon market and other ecosystem-service payment mechanisms. Thus, the conservation community faces a massive funding shortfall to protect the remaining lowland primary forests in Southeast Asia.
\end{abstract}

Front Ecol Environ 2011; 9(6): 329-334, doi:10.1890/100079 (published online 3 Feb 2011)

$\mathrm{A}^{\mathrm{s}}$ oiding greenhouse-gas emissions by reducing the rate of conversion of forests across the globe is widely considered to be a cost-effective means of climatechange mitigation (Stern 2007; Nepstad et al. 2009). Whether through a global mechanism - such as "REDD+" (Reducing Emissions from Deforestation and Forest Degradation or enhancement of carbon stocks) or voluntary offset markets, several studies have suggested that offsetting the opportunity costs of forest conservation will be economical in developing countries, where most of the conversion threat and much of global biodiversity resides (Stern 2007; Kindermann et al. 2008). For example, the Stern Review estimated that up to $50 \%$ of the world's deforestation can be stopped for as little as US\$5 per metric ton of carbon dioxide $\left(\mathrm{tCO}_{2}\right.$; Stern 2007). Others have estimated that a $50 \%$ cut in global deforestation could be achieved at a price of US\$10-\$21 per $\mathrm{tCO}_{2}$ (Kindermann et al. 2008). This latter range could also end deforestation in Brazil within 10 years, according to Nepstad et al. (2007). These seemingly inexpensive mitigation costs have given hope to conservationists that carbon payments in the speciesdiverse tropics can be an effective tool for preventing species extinction (Venter et al. 2009).

At the same time, researchers have noted that the costs of conservation are spatially heterogeneous (Balmford et al. 2003; Naidoo and Iwamura 2007). In some parts of the world, the foregone profits that conservation would entail might be too great to be offset by

${ }^{1}$ Woodrow Wilson School of Public and International Affairs, Princeton University, Princeton, NJ*(bpfisher@princeton.edu); ${ }^{2}$ Institute of Integrative and Comparative Biology, University of Leeds, Leeds, UK; ${ }^{3}$ Department of Ecology and Evolutionary Biology, Princeton University, Princeton, NJ carbon payments. For example, several studies have shown that the expansion of oil-palm plantations into forests in Southeast Asia is a case where carbon payments fail to meet the opportunity costs of conservation, given the lucrative and expanding palm-oil market (Butler et al. 2009; Venter et al. 2009; Persson and Azar 2010). These studies suggest that higher carbon prices (Butler et al. 2009; Venter et al. 2009) or other payments for ecosystem services (Persson and Azar 2010) might help to make the conservation of forests in Southeast Asia more economically competitive with conversion. Understanding the magnitude of the difference between the costs of conservation and the benefits of conversion in this region is critical for several reasons:

(1) Southeast Asia is host to four global biodiversity hotspots, featuring many endemic species across multiple taxa (Myers et al. 2000; WebFigure 1).

(2) The lowland rainforests of Southeast Asia contain large stores of vegetative and soil carbon, with biomass stock estimates as high as 225 metric tons of carbon per hectare ( $\mathrm{tC} \mathrm{ha}^{-1}$; IPCC 2006).

(3) This area currently has the highest rate of deforestation across the tropics (Sodhi et al. 2010). Moreover, this rate is increasing. An upper-bound estimate for remaining lowland dipterocarp forests in western insular Southeast Asia is about $285000 \mathrm{~km}^{2}$, down from an original extent of $\sim 900000 \mathrm{~km}^{2}$ (Figure 1).

(4) Poverty is widespread (Sodhi et al. 2004), making economics an especially crucial consideration in land-use decisions.

(5) Southeast Asia is home to the largest tropical log producers for the global timber, plywood, and veneer markets (Berry et al. 2010), and it produces over 80\% of the world's palm oil (Koh and Wilcove 2007). 


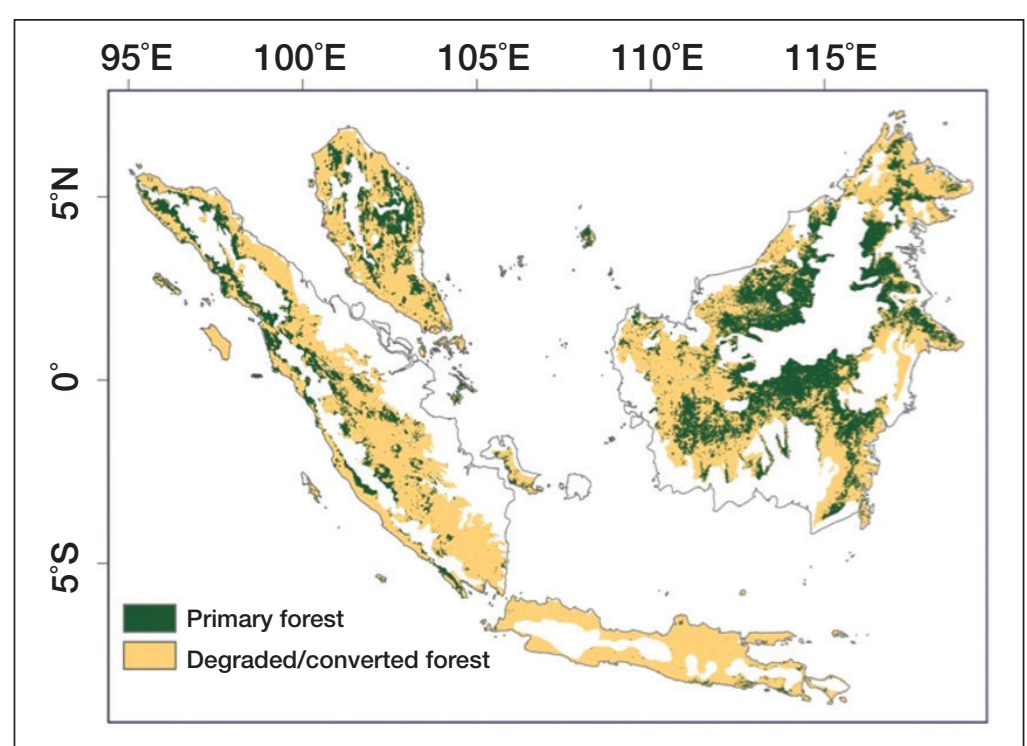

Figure 1. Historical and current extent of lowland dipterocarp forests in western insular Southeast Asia. The current distribution of primary lowland dipterocarp forest is highlighted in green; degraded lowland dipterocarp forests and converted areas are highlighted in beige. This is an upper-bound estimate, because selectively logged areas that have reached structural characteristics (eg height, canopy structure) similar to those of primary forest are classified as primary forests. (Overlay of Moderate Resolution Imaging Spectroradiometer [MODIS]-derived landcover map of western insular Southeast Asia [Miettinen et al. 2008] and the WWF ecoregions of the world map [Olson et al. 2001]. The landcover dataset was produced from 250 MODIS images captured between 1 January 2007 and 2 July 2007, and has a spatial resolution of $500 \mathrm{~m}$.)

Hence, the forests in this part of the world are an example of a location where the conservation of biodiversity and carbon comes up against pressures for conversion due to the magnitude of marketable timber and potential for oil-palm plantations.

Although forest conservation for carbon storage and for biodiversity is not identical, Southeast Asia's rapidly vanishing primary forests do represent ecosystems where the two goals overlap (Venter et al. 2009; Strassburg et al. 2010). Thus, an accurate understanding of the monetary gap - between the cost of conserving these forests and the financial benefits gained from converting them - is critical if (1) the conservation community is to know the full extent of the funding needed for conservation and (2) national governments and decision makers are to gauge how they will meet emissions reduction targets, biodiversity commitments, and development objectives.

Here we provide an accurate calculation of the financial gap by using detailed logging records, cost data, and auction prices from Malaysian Borneo. Previous studies have not had access to similar logging records. We first calculate the opportunity costs for timber and oil-palm conversion in lowland dipterocarp habitats. We investigate what the equilibrium price (or "breakeven price") for carbon would have to be to offset the financial benefits of both logging and oil-palm conversion. We then look at current levels of financial payments for other ecosystem services that could theoretically be applied in lowland rainforests in Southeast Asia, to identify the role that non-carbon-related payments for ecosystem services (PES) schemes could play in offsetting conservation costs.

We find that in Malaysian Borneo, the profitability of logging, in combination with potential profits from palm oil, means that - even with a global carbon market and other PES mechanisms - the conservation community faces a massive funding shortfall to protect the remaining primary forests in this region. Furthermore, research has shown that comparable timber extraction rates (Marsh and Greer 1992; Holmes et al. 2002; Curran et al. 2004) and profits exist for lowland rainforests across Southeast Asia (Sheeran 2006), suggesting that if extraction costs and techniques are similar, our results may apply to much of the remaining lowland forest in this biodiverse region.

\section{Methods}

\section{Timber data}

We compiled logging records from Sabah, Malaysian Borneo, from the past four decades in order to calculate the volume of wood removed and the net profits from commercial logging (all monetary figures hereafter are in 2009 US dollars; price and cost values from other years were inflated using the Consumer Price Index [CPI] as the inflation method). Forests in this area are dominated numerically by large tree species in the family Dipterocarpaceae (Johns 1996). These forests were selectively logged following a modified uniform system (Whitmore 1984), in which virtually all commercially valuable tree species $>40 \mathrm{~cm}$ diameter at breast height (dbh) were removed by way of tractor and cable extraction techniques, over two rotations. The first rotation allowed the removal of all stems $>60 \mathrm{~cm} \mathrm{dbh}$, and the second rotation allowed additional removal of stems $>40 \mathrm{~cm}$ $\mathrm{dbh}$ from the same coupes (distinct logging areas - sometimes known as compartments) 15-30 years later. Records for over 220000 ha of forest where rights to logging were legally granted (known as "logging concessions") were analyzed, and we calculated the mean volume extracted per hectare on a species-by-species basis (WebTable 1). All records are from the Yayasan Sabah Forest Management Area, where detailed pre-logging and postlogging censuses were required, and where all tree species marked for removal were noted and measured. We used official government auction market data (mean from 2007-2009) from Sabah for the 12 most common species extracted and for one general class, as well as local cost data for logging activities and for delivering timber to the 
market in order to calculate the net profit of logging these forests (FRIM and ITTO 2001; WebTables 1 and 2). Cost data come from carefully monitored, conventional logging operations on 364 ha in a single logging coupe, with costs reported by the State Forest Department, the District Forest Office, the concessionaire (those with rights to $\log$ ), and contractors (those carrying out the logging; FRIM and ITTO 2001). We calculated net returns in two ways: (1) assuming all timber was removed at first rotation (Equation 1 ) and (2) using two rotations and discounting values from the second cut based on the mean difference in years between first rotation and second rotation (Equation 2). The first method represents a high estimate of future timber returns and is rationalized by the fact that the minimum diameter-cutting limit changed over the life of the concessions. The second represents a low estimate of future returns and assumes that previous standards can be enforced. The net profit of timber was calculated as follows:

$$
R_{T}=\sum_{x}^{X}\left(V_{x a} * p_{x}\right)-C_{a}
$$

$R_{1,2}=\sum_{x}^{X}\left\{\left[\left(V_{x a 1} * p_{x}\right)-C_{a}\right]+\frac{\left[\left(V_{x a 2} * p_{x}\right)-C_{a}\right]}{(1+r)^{n}}\right\}$

where $R_{T}$ is the net rent (cost in dollars per hectare) of logging in area $a$ when first and second rotations are combined into one offtake; $V_{x a}$ is the volume of species $x$ in area $a ; p_{x}$ is the 3 -year mean market price for species $x$; and $\mathrm{C}_{a}$ is the cost of logging in area $a$ (including taxes and costs associated with felling, skidding [dragging logs through forested areas to trucks], transportation, and so forth; WebTable 2); and a represents an average hectare (based on mean volume) of forest from the 220000 ha of logging records. In Equation 2, the rotations are separated and summed $\left(R_{1,2}\right)$, and $V_{x a 1}$ becomes the volume of species $x$ removed from area $a$ in the first rotation. $V_{x a 2}$ is the volume of species $x$ removed from area $a$ in the second rotation. The values from the second rotation are discounted by $r(r=10 \%)$ over the mean difference in years between coupe rotations $n$ ( $n=16$ years). Timber prices and costs are kept constant, given the complexity of forecasting individual parameters in 16 years' time, but it is assumed that the cost and benefit side of the equation will be equally affected in the future.

\section{Oil-palm profit}

We calculated the net returns from oil-palm plantations using existing data and recent market prices for crude palm oil (CPO; see WebTable 3 for data and sensitivity analysis). This market is expected to expand over the next few decades on account of the versatility of palm oil as a component in many consumer products and an expected rise in demand for biofuels (Persson and Azar
2010). The net present value (NPV) of an oil-palm plantation, assuming all the timber has been removed, was calculated as follows:

$$
P=-(L+S)+\sum_{1}^{25} \frac{(y * p)-c}{(1+r)^{n}}
$$

where $P$ is the NPV of an oil-palm plantation ( $\$$ per hectare); $L$ is the cost of land ( $\$$ per hectare); $S$ is the setup cost for a plantation ( $\$$ per hectare); $y$ is the mean yield over the 25-year lifespan of a "good practice" plantation (metric tons CPO per hectare; Persson and Azar 2010); $p$ is the market price for a metric ton of $\mathrm{CPO} ; c$ is the cost of harvesting and processing the mean yield each year ( $\$$ per hectare); $r$ is the discount rate, set at $10 \%$; and $n$ is the time horizon of the project, set at 25 years.

\section{PES values}

We searched three databases for non-carbon-related PES schemes operational across the tropics and not limited to Southeast Asia. The databases combined over 600 entries for market-based conservation interventions (see WebTable 4). We used the highest per-hectare values available for water regulation, biodiversity, and scenic and recreational payments as an optimistic indication of what PES might deliver in our context.

\section{Carbon price equilibrium}

In order to find the carbon price that offsets profits from logging and oil palm, we calculated an equilibrium $\mathrm{CO}_{2}$ price $\left(\$\right.$ per $\left.\mathrm{tCO}_{2}\right)$ as follows:

$$
E=\frac{(R+P)}{3.67 *\left(Z_{r}+Z_{p}\right)}
$$

where $E$ is the equilibrium carbon price needed to offset the opportunity costs of conservation $\left(\$\right.$ per $\left.\mathrm{tCO}_{2}\right) ; \mathrm{R}$ is the net rent from logging ( $\$$ per hectare); $P$ is the net rent from oil-palm plantations ( $\$$ per hectare); $Z_{r}$ is the carbon emitted from logging operations $(\mathrm{tC})$ including aboveground biomass, litter pools, and soil carbon; $Z_{p}$ is the additional carbon emitted from these pools by converting logged land into oil palm ( $\mathrm{tC})$; and 3.67 is the conversion constant for converting metric tons of carbon into metric tons of $\mathrm{CO}_{2}$ (see WebTable 5).

\section{Results}

\section{Timber values}

We find that logging primary dipterocarp rainforest yields a mean offtake of $152( \pm 17) \mathrm{m}^{3} \mathrm{ha}^{-1}$ (Figure 2). Using species-specific auction prices from the Sabah government 


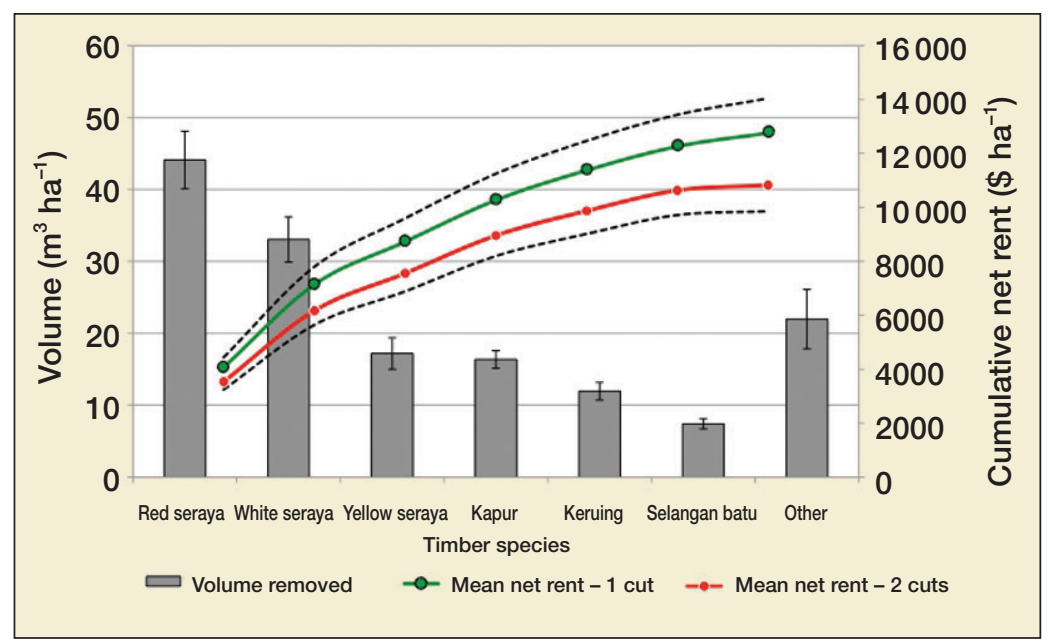

Figure 2. Volume of timber removed per hectare by species and cumulative profit. The 13 species assessed are collapsed here to show the six species with the highest extraction volumes per hectare along with a general category ("Other") for the remaining seven species. The overall mean profit from all timber classes is between $\$ 9860$ per hectare (red curve, Equation 2) and $\$ 12750$ per hectare (green curve, Equation 1) with about 70\% of that coming from just three species: red, white, and yellow seraya (Shorea $s p$ ). Dashed lines and error bars show \pm 1 standard error (SE). Selangan batu (Shorea $s p$ ); kapur (Dryobalanops aromatica); keruing (Dipterocarpus sp).

lots (WebTable 1) and local costing data (FRIM and ITTO 2001), we calculate that this level of logging returns a mean profit of $\$ 9860-\$ 12750$ per hectare. From empirically based modeling, we know that this level of logging in lowland dipterocarp rainforests corresponds to approximately 124 metric tons of carbon removed per hectare (Pinard and Cropper 2000; WebTable 5). At this level of timber extraction, carbon payments would have to be between $\$ 22-\$ 28$ per $\mathrm{tCO}_{2}$ to overcome the profit gained from logging.

\section{Timber and oil palm}

Because the areas where lowland rainforests occur are often ideal for agricultural development, the full opportunity cost of conservation includes post-logging agricultural returns, primarily from oil palm (Koh and Wilcove 2008). Calculations of the potential returns from oil-palm plantations in this region vary widely, from $\$ 4000$ per hectare to $\$ 29000$ per hectare (Koh and Wilcove 2007; Butler et al. 2009; Noormahayu et al. 2009; Persson and Azar 2010) under a range of assumptions. Our calculation of net returns from oil palm over a 25-year life cycle $(r=10 \%)$ falls within this range, at $\$ 11240$ per hectare (WebTable 3 ). We calculated our own value, rather than use the wide range available from the literature, in order to: (1) avoid double counting of timber values; (2) use a standard discount rate and time horizon comparable with our logging estimate; and (3) use the latest cost, price, and yield data available from previous studies (WebTable 3 ).

Conversion to oil palm nearly doubles the net rent from a single hectare of forest, but also emits an additional 13 metric tons of carbon (48 tons of $\mathrm{CO}_{2}$ equivalent, or
$\mathrm{tCO}_{2 \mathrm{eq}}$; Gibbs et al. 2008). To overcome the opportunity cost of conservation with respect to both timber and oil palm, a REDD+ mechanism or carbon market would have to offer $\$ 46-\$ 48$ per $\mathrm{tCO}_{2}$ (Figure 3).

\section{The role of additional ecosystem-service payments}

We investigated how large a contribution non-carbon-related PES schemes could make to the financial feasibility of conservation in Southeast Asia. We ignored the fact that PES should be performance-based and spatially targeted, and simply picked the largest perhectare payments for watershed protection, biodiversity, and scenic beauty/recreational value currently being made in the tropics. Adding watershed protection payments $(\$ 188$ per hectare per year), biodiversity payments ( $\$ 50$ per hectare per year), and scenic and recreational payments $(\$ 50$ per hectare per year) into our conservation argument increases the value of standing forests by $\sim 2700$ per hectare (NPV $r=10 \%$ over 30 years; WebTable 4 ). This represents about $11 \%$ of the opportunity cost of conservation relative to logging and oil-palm returns. With these additional - yet hypothetical - payments, the breakeven carbon payment would be reduced to $\$ 40-\$ 42$ per $\mathrm{tCO}_{2}$, including setup and monitoring costs.

\section{Discussion}

Previous studies have documented the threat to Southeast Asian forests posed by oil-palm agriculture (Koh and Wilcove 2007; Butler et al. 2009). Our results show that in addition to the profits from oil palm, even larger profits exist from one-time logging activities. Together these two activities impose a sizable opportunity cost of conservation in some of the world's most threatened and diverse forest systems.

Several lines of evidence suggest that our findings from Sabah could apply to much of the lowland dipterocarp forests elsewhere in Southeast Asia. Extraction rates in mixed dipterocarp forests under the minimum diameter cutting limits (MDCL) are similar $\left(100-150 \mathrm{~m}^{3} \mathrm{ha}^{-1}\right)$ across the region (Marsh and Greer 1992; Holmes et al. 2002; Curran et al. 2004). Similar profits from logging have been shown for dipterocarp forests in the Philippines (Sheeran 2006). Moreover, lowland forest sites throughout Southeast Asia are generally well suited for oil-palm plantations. Nonetheless, it remains to be seen if logging costs in Sabah are comparable to costs elsewhere in the region.

Using the European Trading Scheme (ETS) market price for $\mathrm{CO}_{2}$ (2009 end-of-year price of $\$ 17.40$ per $\mathrm{tCO}_{2}$ ), we 
estimate that protecting each hectare of primary lowland forest would require an additional \$13 200-\$16 000 to offset the opportunity costs of conservation (Figure 3). By adding PES funds, this gap can be narrowed to $\$ 10500-\$ 13300$ per hectare. This unmet portion of the opportunity cost poses a nearly insurmountable barrier to conservation. For example, protecting another area of primary lowland forest comparable to the Danum Valley Conservation Area (43 800 ha) in Sabah, Malaysian Borneo, assuming all of the land is suitable for oil palm, would require carbon payments and other PES schemes plus an additional payment of $\$ 460 \mathrm{mil}$ lion-\$580 million.

Previous cost analyses suggest that much of the world's deforestation and forest degradation could be mitigated for carbon payments as low as $\$ 5-\$ 10$ per $\mathrm{tCO}_{2}$ (Nepstad et al. 2007; Stern 2007; Kindermann et al. 2008), four to nine times cheaper than the results from our analysis. Thus, in a competitive carbon market, it is difficult to envision Asia's dipterocarp forests competing with forests in other parts of the world. At the same time, mid- and long-term carbon market forecasts span three orders of magnitude, from $<\$ 1$ to $>\$ 100$ per $\mathrm{tCO}_{2}$ (Ecosecurities 2009), suggesting at least the possibility that by mid-century, conservation in these lowland rainforests could compete financially with conversion. However, the high rate of deforestation in the region underscores the fact that understanding the financial constraints to conservation is essential in the near term.

While the current financial implications of logging and the establishment of oil-palm plantations seem clear, the political reality of how REDD+ will operate "on the ground" is not. It seems certain that REDD+ will function through governments at the national level, and the potential flows of money through REDD+ are likely to exceed both global conservation funding and many national forestry budgets (Phelps et al. 2010). If decision-making power, with regard to spatial planning, resides at the national level, carbon payments might not have to overcome the full opportunity cost, because guaranteed money to federal coffers might trump future - and more distributed - returns stemming from logging operations and oil-palm plantations. However, in countries like Indonesia and Malaysia, land-use planning power often resides at the provincial/state level. Thus, negotiations between federal and provincial/state-level authorities will be critical in determining whether REDD+ succeeds. Moreover, national governments are likely to take into account the secondary and even tertiary effects on employment and tax revenue stemming from logging and oil-palm agriculture before embracing conservation incentives such as REDD+ (Ghazoul et al. 2010). For example, the Indonesian
Government recently signed a letter of intent with the Norwegian Government to accept $\$ 1$ billion in exchange for reduced emission activities via forest protection, but the initial deal includes only a 2-year suspension of conversion of forests for "new" concessions, and this suspension might not be put into effect until 2013 (Lang 2010).

We did not analyze the temporal or spatial feedbacks that could affect our results, but rather worked on a "per hectare" basis, representing the next unit of conversion. Future increases in the global supply of timber from the logging of natural forests and plantations elsewhere in the tropics could affect the net returns from logging in Southeast Asia, perhaps making conservation in this region more cost effective. Changes in demand for and sources of biofuels could also lower the profitability of conversion in Southeast Asia through global market forces. However, our objective, given the rapid rate of forest conversion in Southeast Asia, is to assess the current gap between the real financial values of rainforest conversion and current or proposed mechanisms to stem such conversion. We find that the massive timber values driving deforestation in Southeast Asia have been largely overlooked in recent analyses, which have focused mainly on the role of REDD+ in offsetting agricultural opportunity costs (Butler et al. 2009; Venter et al. 2009). Even the incorporation of other ecosystem services at current prices fails to change this situation. 
Our results point to the difficulty of protecting primary lowland forests in Southeast Asia in the absence of extraordinary financial inputs or foregone revenues. Thus, in many cases, conservationists will have to focus on areas that are difficult to access for timber or are unsuitable for oil palm, severely restricting the scope of conservation activities. Alternatively, conservationists can accept protection strategies that incorporate an initial offtake of timber, or management of production forests (forests managed for the extraction of timber). Previous studies have shown that logged forests retain most - but not all forest-dependent species across a range of taxa (Berry et al. 2010; Edwards et al. 2011). Securing already logged areas would lessen the opportunity cost of conservation but would also limit the revenue available from carbon payments. Understanding this balance between preservation and production forests will likely become a critical area of investigation in the coming decade.

\section{Acknowledgements}

Helpful comments and discussion from F Ansell, LP Koh, R Naidoo, M Potts, and C Roberts greatly improved this manuscript. We thank A Abi at the Sabah Forestry Department. We are grateful to the High Meadows Foundation for support of this work.

\section{References}

Balmford A, Gaston KJ, Blyth S, et al. 2003. Global variation in terrestrial conservation costs, conservation benefits, and unmet conservation needs. P Natl Acad Sci USA 100: 1046-50.

Berry NJ, Phillips OL, Lewis SL, et al. 2010. The high value of logged tropical forests: lessons from northern Borneo. Biodivers Conserv 19: 985-97.

Butler RA, Koh LP, and Ghazoul J. 2009. REDD in the red: palm oil could undermine carbon payment schemes. Conserv Lett 2: 67-73.

Curran LM, Trigg SN, McDonald AK, et al. 2004. Lowland forest loss in protected areas of Indonesian Borneo. Science 303: $1000-03$.

Ecosecurities. 2009. Forecasting the future value of carbon: a literature review of mid- to long-term carbon price forecasts. Portland, OR: Ecosecurities Consulting Ltd.

Edwards DP, Larsen TH, Docherty TDS, et al. 2011. Degraded lands worth protecting: the biological importance of Southeast Asia's repeatedly logged forests. P Roy Soc B 278: 82-90.

FRIM (Forest Research Institute Malaysia) and ITTO (International Tropical Timber Organization). 2001. A model project for cost analysis to achieve sustainable forest management: volume 1 synthesis report. Kepong, Malaysia: FRIM and ITTO.

Ghazoul J, Butler RA, Mateo-Vega J, and Koh LP. 2010. REDD: a reckoning of environment and development implications. Trends Ecol Evol 25: 396-402.

Gibbs HK, Johnston M, Foley JA, et al. 2008. Carbon payback times for crop-based biofuel expansion in the tropics: the effects of changing yield and technology. Environ Res Lett 3, doi: $10.1088 / 1748-9326 / 3 / 3 / 034001$.

Holmes TP, Boltz F, and Carter DR. 2002. Financial indicators of reduced impact logging performance in Brazil: case study comparisons. In: Enters T, Durst PB, Applegate GB, et al. (Eds) Applying reduced impact logging to advance sustainable forest management. Bangkok, Thailand: Food and Agriculture
Organization of the United Nations, Regional Office for Asia and the Pacific.

IPCC (Intergovernmental Panel on Climate Change). 2006. IPCC guidelines for national greenhouse gas inventories. Hayama, Japan: National Greenhouse Gas Inventories Programme.

Johns AG. 1996. Bird population persistence in Sabahan logging concessions. Biol Conserv 75: 3-10.

Kindermann G, Obersteiner M, Sohngen B, et al. 2008. Global cost estimates of reducing carbon emissions through avoided deforestation. P Natl Acad Sci USA 105: 10302-07.

Koh LP and Wilcove DS. 2007. Cashing in palm oil for conservation. Nature 448: 993-94.

Koh LP and Wilcove DS. 2008. Is oil palm agriculture really destroying tropical biodiversity? Conserv Lett 1: 60-64.

Lang C. 2010. Norway-Indonesia forest deal: US\$1 billion dollars worth of continued deforestation? REDD-Monitor. www.reddmonitor.org/2010/05/28/norway-indonesia-forest-deal-us1billion-dollars-worth-of-continued-deforestation/. Viewed 6 Dec 2010.

Marsh CW and Greer AG. 1992. Forest land-use in Sabah, Malaysia: an introduction to Danum Valley. Philos T Roy Soc B 335: 331-39.

Miettinen J, Wong CM, and Liew SC. 2008. New 500-m spatial resolution land cover map of the western insular Southeast Asia region. Int J Remote Sens 29: 6075-81.

Myers N, Mittermeier RA, Mittermeier CG, et al. 2000. Biodiversity hotspots for conservation priorities. Nature 403: 853-58.

Naidoo R and Iwamura T. 2007. Global-scale mapping of economic benefits from agricultural lands: implications for conservation priorities. Biol Conserv 140: 40-49.

Nepstad D, Soares-Filho BS, Merry F, et al. 2007. The costs and benefits of reducing carbon emissions from deforestation and forest degradation in the Brazilian Amazon. Falmouth, MA: Woods Hole Research Center.

Nepstad D, Soares-Filho BS, Merry F, et al. 2009. The end of deforestation in the Brazilian Amazon. Science 326: 1350-51.

Noormahayu MN, Khalid AR, and Elsadig MA. 2009. Financial assessment of oil palm cultivation on peatland in Selangor, Malaysia. Mires and Peat 5: 1-18.

Olson DM, Dinerstein E, Wikramanayake ED, et al. 2001. Terrestrial ecoregions of the world: a new map of life on Earth. BioScience 51: 933-38.

Persson UM and Azar C. 2010. Preserving the world's tropical forests: a price on carbon may not do. Environ Sci Technol 44: 210-15.

Phelps J, Webb EL, and Agrawal A. 2010. Does REDD plus threaten to recentralize forest governance? Science 328: 312-13.

Pinard MA and Cropper WP. 2000. Simulated effects of logging on carbon storage in dipterocarp forest. J Appl Ecol 37: 267-83.

Sheeran KA. 2006. Forest conservation in the Philippines: a costeffective approach to mitigating climate change? Ecol Econ 58: $338-49$.

Sodhi NS, Koh LP, Brook BW, and Ng PKL. 2004. Southeast Asian biodiversity: an impending disaster. Trends Ecol Evol 19: 654-60.

Sodhi NS, Posa MRC, Lee TM, et al. 2010. The state and conservation of Southeast Asian biodiversity. Biodivers Conserv 19: 317-28.

Stern N. 2007. The economics of climate change: the Stern Review. Cambridge, UK: Cambridge University Press.

Strassburg BBN, Kelly A, Balmford A, et al. 2010. Global congruence of carbon storage and biodiversity in terrestrial ecosystems. Conserv Lett 3: 98-105.

Venter O, Meijaard E, Possingham H, et al. 2009. Carbon payments as a safeguard for threatened tropical mammals. Conserv Lett 2: 123-29.

Whitmore TC. 1984. Tropical rain forests of the Far East. New York, NY: Oxford University Press. 